\title{
Employee Trust and Ethical Leadership Decision Making
}

\author{
Evangelia Fragouli
}

University of Dundee, UK

\begin{abstract}
Organizations that encourage a trusting culture are believed to have a competitive advantage on ethical decision-making. Part of a leader's functions is to work with employees to find problems within an organization and solve them. The ease at which a leader gains access to the information they need to make ethical decisions and solve problems depends on how much employees trust them, and how much they (leaders) trust employees. This study examines the role of employee trust on ethical leadership decision making. It explores the role of employees trust towards their leaders' ethical decision making and how a lack of employee trust (mistrust) in an organization affects ethical leadership decision making. The research methodology employed in this study is literature review and it was aimed at addressing critically the role of employee trust (and lack of that) towards leadership ethical decision making. The findings of this study indicate that when leaders are trusted by their employees, they are forced to prove their competence and ethics in the decisions they make. It also shows that when employees are trusted by their leaders, they encounter a feeling of indefinite responsibility to show signs of goodness towards their leaders and this influences ethical decision making. A lack of trust between employees and their leaders weakens relationships, causes suspicion, deception and affects a leader's decision making ethics.
\end{abstract}

Keywords:

Trust, Ethical, Leadership, Decision Making

\section{Introduction}

"The only way to make a man trustworthy is to trust him, and the surest way to make him untrustworthy is to distrust him and show your distrust" - Henry L. Stimson. Trust is a fundamental construct which is usually thought of as a mental situation in which employees make themselves vulnerable in their work relationships basing upon expectations, assumptions and beliefs that their leader's decisions will be positive, beneficial and favourable (Lee et.al, 2010). That is, trust indicates the eagerness of an employee to be vulnerable to the decisions of their leader and is an indication of 
confidence that their vulnerability will not be exploited and will not be harmed by the leader's decisions.

Obtaining employee trust is an important element of becoming a successful leader and is a vital element by which the work effectiveness of the employees can be improved (Hsieh et.al, 2015). Trust in an organization binds leaders and employees together, and it is the most unmediated and influential way in which a leader promotes organizational effectiveness (Boyton \& Mishra, 2014). It promotes cooperation between the leader and the employee and further facilitates good ethics and decision making. Leaders who portray ethical leadership and who have their employees recognize their decisions as ethical improve the trust that employees have in them. They feel attached to each other, and the employees appreciate their work more (Jiang \& Probst, 2016). An employee's trust on their leader has a moderating outcome in their leader's decision making (Spreitzer \& Mishra, 2014). Through trust, leaders indulge employees in the decision making process with a belief that employees will not take advantage of this shared responsibility because their leaders are concerned with the interests of the organization (Hurley, 2006).

\section{Business, Ethical Leadership \& Employee Trust}

In the business world, the concept of ethics has played a crucial role since the beginning of the twenty-first century due to two significant factors. First, employers became aware that ethical conduct has positive effects on the employees' performance and the organisation's profitability (Yang, 2014). Second, a recent number of business scandals have made firms realise the great risk involved in facing such an event (Lu and Lin, 2014). In addition, ethics has become one of the most important issues for governments. This is because unethical leadership decisions may impact negatively not only business organisations but also the daily lives of millions of people (Stenmark and Mumford, 2011). Furthermore, unethical leadership decisions pose a direct threat to firms ( $\mathrm{Lu}$ and $\mathrm{Lin}, 2014$ ). For instance, according to the Ethics Resource Center (2012), 52\% of employees do not trust their leader because of their unethical behaviour. Moreover, some studies showed that unethical conduct damages the reputation of these firms, which reduces the long-term profit due to customers being unwilling to do business with them. In addition, the financial risk of such firms rises naturally and this means extra financial costs, lower firm value and diminishing stakeholders' returns (Lu and Lin, 2014).

In the literature dealing with ethical leadership, trust in leadership has been one of the crucial topics for researchers for several decades, having been studied within a number of different fields, including psychology, management, ethics, and other related disciplines (Dirks and Ferrin, 2002). In an organisational setting, the trust between employee and leader is significant as trust increases the level of cooperative relationships, which can provide important positive outcomes for organisations (Brower et al., 2008). Evidence suggests that employees' attitudes are directly proportionate to the performance of a firm. A variety of other factors impact employees' attitudes, with trust in leaders being recognised as playing a significant role (Wang et al., 2011). Whilst there have been numerous studies on how a leader's behaviour and decisions affect employee trust, little research has focused on the impacts of employee trust on ethical leadership decision making (Stenmark and Mumford, 2011).

\section{Ethical Leadership Decision Making}

The ethical environment and culture in organisations gained greater attention from both academics and practitioners in examining antecedents and outcomes of ethical leadership. As demonstrated by numerous empirical and theoretical studies, ethical leadership results in improved employee outcomes such as satisfaction and commitment, coming forward to report problems to the supervisors, job dedication, and improved overall performance (Chughtai et al., 2015). However, although there are lots of rules and regulations to avoid unethical issues in the business world, such events still occur 
frequently. That is why ethical leadership is currently such an important issue in organisations (Steinbauer et al., 2014). Leaders should demonstrate ethical behaviour in both their professional and private lives because in organisations leaders are role models and provide ethical guidance for their followers. Followers observe their leader, learning what they should and shouldn't do and, after some time, begin imitating their leader's behaviour (Van Den Akker et al., 2009). Ethical leadership theory explains how employees' ethical decisions and actions are affected by their leader's ethical behaviour through social learning processes. In addition, a number of tools that help leaders create an ethical organisation are available, such as setting up ethical standards, social exchange processes, and using performance management systems (Steinbauer et al., 2014).

Brown et al. (2005, p. 120) defined ethical leadership in their study as 'the demonstration of normatively appropriate conduct through personal actions and interpersonal relationships, and the promotion of such conduct to followers through two-way communication, reinforcement, and decision making'. According to Chughtai et al. (2015) there are two dimensions of ethical leadership: the moral person and the moral manager. The former includes personality characteristics, attributes and the altruistic motivation of the leader, whilst the latter includes ethical leaders who show honesty and are perceived as fair and principled decision makers, who show care and concern for their followers and transform them by modelling ethical behaviour, communicating ethical standards and holding followers responsible for ethical actions. Also, an empirical research study identified the term ethical leadership from the perspective of employees. According to the results, although there are many personal characteristics and skills related to ethical leadership, two of them were found to be the most dominant: honesty and trustworthiness. In addition, the study provided evidence about moral management, which is another significant aspect of ethical leadership, referring to the impacts of ethical leadership decisions on employees' ethical and unethical behaviours (Brown and Treviño, 2006).

\section{Employee Trust}

In an academic context, the number of studies investigating trust has been steadily increasing, expanding to include sociology, psychology, economics, management, and ethics. A number of studies on employee trust in the organisations have shown that trust supports many significant work outcomes, such as employee performance, job satisfaction, and organisational responsibility (Frazier et al., 2016). For example, an empirical study conducted by Jafri (2011) showed that employees' trust in the leader influences and improves innovative behaviour and the employees overall. Trust also strongly impacts the effectiveness and normative commitment of employees. These positive contributions are quite important in the contemporary business world because they ultimately lead to the development of the organisation and its performance.

Although those who have studied trust claim that the definition of trust derives from numerous aspects, it is widely acknowledged that not enough has been done to converge on a widely accepted definition. However, the term has been scrutinised, with numerous researchers attempting to create a definition in order to draw conclusions about its impacts and nature (Whitener, 1998). Despite the concept of trust having been defined in lots of different ways, a large number contain some common elements, such as concern of dependability, vulnerability of dependency, and expectations. In this context, the definition of trust is, "A psychological state comprising the intention to accept vulnerability based upon positive expectations of the intentions or behaviours of another" (Lau and Liden, 2008, p.1131). As noted, the purpose of this paper is to explore employee trust in the organisation's leadership and to examine its impacts on ethical leadership decision making. The definition of trust in the organisation is not exactly the same as the definition of interpersonal trust. The definition in terms of employees and the workplace refers to not a single person but an 
organisation or a system. In line with this, the definition of employee trust is an individual's expectation, which is both foreseeable and bona fide. In addition, employee trust involves reliability and faith in the basic rules and principles of the organisation (Weibel et al., 2016).

\section{The Relationship between Employee Trust and Ethical Leadership Decision Making}

Numerous studies have demonstrated the strong relationship between employee trust and ethical leadership within an organisation, and how each impacts the other to some degree (Gomibuchi, 2004). In addition to focusing on the effects of employee trust on ethical leadership decisions, this research paper may benefit from examining the two different aspects in order to better understand the relationship, with a particular emphasis on, first, the impact of ethical leadership decisions on employee trust in an organisation and, second, how employee trust affects the ethical leadership decisions.

First is the impact of ethical leadership decisions on employee trust. One of the major tasks of a leader is to build trust within the organisation, and a number of empirical studies demonstrating that ethical leadership behaviours and decisions increases employee trust in the leader and the organisation (Brower et al., 2008). For example, Van Den Akker et al. (2009) examined effects of leadership on employee trust by using a web-based survey. A total of 500 employees who are from 16 different European countries participated in the survey. According to the results from employees' perceptions, ethical leadership behaviours and decisions directly affect level of employee trust in their leaders.

Second is the role of employee trust on the ethical leadership decision. Although literature has not yet provided any solid evidence to show exactly how employee trust impacts ethical leadership decision making, aspects of this may be revealed by using previous relevant studies. For example, several behavioural mechanisms frequently affect leadership decisions (Stenmark and Mumford, 2011). First, behavioural reasoning theory may be useful to explain how employee trust influences leadership decisions in terms of ethics. According to behavioural reasoning theory employee attitudes affect leaders' intentions. This relationship has significant impacts on leader decisions because employee attitudes create a moral way for the leader. That is why, in the future, the leader will try to act same way to keep same his or her subordinate's attitudes because if the leaders change their moral behaviors in negative side, employees' attitudes move to negative side against their leader. For example, take a leader who always tries to make ethical decisions. When this leader is confronted with a scenario that is potentially damaging to some employees, he or she may feel social pressure not to do it; however, the leader may still intend to go ahead with this decision due to his or her specific reasons for engaging in the ethical behaviour (Westaby et al., 2010). In addition, there is a strong relationship between employee trust and employee attitudes towards their leaders. A number of studies have shown that the level of employee trust affects positively employees' behaviours and attitudes against their leader and the organisation (Brower et al., 2008). When these two relationships (employee attitudes - leaders' intentions and employee trust - employee attitudes) are present, evidence suggests that employee trust has an indirect positive impact on ethical leadership decision making.

Another approach regards the social learning theory. Followers observe the decision makers and judge them. At the same time, leaders observe the attitudes of his or her subordinates on whether they think the decision was correct or not. In addition, followers pay more attention to the leadership decisions that have greater impact on the organisation or some followers. That is why the magnitude of the result of the decision is significant for leaders because when the potential harm level of the decision is high, the level of judgement by the followers will be high. Thus, the importance of decisions in terms of its consequences and level of pressure on the decision maker is directly proportional (Brown and Treviño, 2006). When reviewing a process of ethical decision making 
whereby the leader wants to sack certain workers, the leader's decision is based on the concept that these employees do not display enough job performance to warrant staying in the organisation. Before making this decision, the leader may consider whether the other employees will support or react negatively to the situation. If he or she does not, this situation could be considered unethical because it goes against the interests of the organisation. This is an ethical dilemma for the decision maker (Westaby et al., 2010). In organisations, people have to make a lot of similar decisions that include moral issues or ethical dilemmas. However, most of these decisions are made under organisational pressures. Thus, this kind of decision may cause stress for the decision makers (Selart and Johansen, 2011). In organisations, trust is reciprocal. If employees trust in their leader and organisation, the leader consequently trusts his or her subordinates (Jafri, 2011). According to Jackson and Parry (2011), employee trust gives the leader confidence when deciding on an important issue. Moreover, trust may play a fundamental role in ethical decisions. According to Lee and Selart (2014), employee trust may cause a feeling of guilt for the leader. Within a trustor-trustee relationship, when people make an unethical decision against trustors, they feel guilty in future. That is why it can be said that employee trust may help leaders to avoid unethical decisions.

Alternatively, Lee and Selart (2014) examined the relationship between trust and ethical decision making. According to the research, trust may have both a positive and negative impact on ethical decision making due to the different dimensions of trust. For instance, trust may produce negative stress for the decision makers. Within an organisational setting, stress is one of the significant variables that affects leadership decisions in terms of ethics. Selart and Johansen (2011) examined stressful situations related to leadership decisions. According to the results, stress may result in less awareness about ethical issues, thus leading to poor ethical decisions being made. Evidence therefore suggests that employee trust may cause poor ethical leadership decisions due to rising levels of negative stress on behalf of the leader.

Another way to demonstrate indirectly how employee trust influences ethical leadership decision making is through performance pressure. The impact of performance pressure was examined by Stenmark and Mumford (2011), who found it to be one of the most important variables negatively affecting the ethical leadership decision-making process. Conversely, employee trust in their leaders may reduce this pressure because it is directly proportionate to employee work performance. There are number of empirical studies about this relationship. For instance, the results of the study carried out by Colquitt et al. (2007) showed that there is a strong positive relationship between employee trust and job performance. In addition, a similar relationship was observed between trust and job satisfaction, though not as strongly. Other significant findings of this study were that trust was positively correlated with level of risk taking and commitment among employees. Employee trust increases job performance and high job performance reduces performance pressure on the leader. That is why it can be said that employee trust may indirectly have a positive impact on ethical leadership decisions.

\section{Trust Influences Communication and Leader Ethical Decision Making}

An organization's communication practices have a direct impact on the level to which employees trust their leaders. When employees believe that their leader can be trusted, is competent and cares about them, they will be more prepared to share their views and opinions with them. Trust in a working environment promotes the exchange of information and is related to high anticipations of honesty and openness between leaders and employees (Wheatcroft et.al, 2012). Trusted leaders usually trust their employees back and do not believe that the information that they share with them will be used opportunistically and to the employees' advantage. (Kaptein, 2011) as cited in (Kimmel et.al. 2011) states that the ability of employees to show trust in their leaders makes the leaders more willing to be 
open and honest with the decisions they make. When there is trust and higher informational exchange between the leader and employees, there is also less use of pressure tactics in decision making as compared to organizations with lower levels of trust (Kimmel et.al. 2011). A high level of trust in an organization makes leaders to show fewer opportunistic behavioural tendencies, and they tend to behave in ways that promote ethicality. Trusted leaders participate in actions that promote the trust of employees. They focus more effort and energy on making sure that they are fair, dependable and that their employees are rewarded fairly (Dirks \& Ferrin, 2002).

When there is trust from the employees, leaders develop and exhibit a genuine concern for the wellbeing of their employees. They include employees in the organization's decision-making processes and pro-actively and openly communicate organizational expectations (Xu et.al, 2016). They channel their organizational expectations to employees through an open two-way communication, listening to what employees say, and asking them "what is the right thing to do?" when making decisions (Xu et.al, 2016). They also prioritize on the compliance to ethical decisionmaking and draw the focus of their employees to the organization's fair and ethical standards (Loi, 2014).

\section{Trusted Leaders Become Moral Agents of the Organization}

Trusted leaders lead their employees in doing things the right way in terms of equitable sharing of outcome. They reward employees' ethical behaviour and curb unethical behaviour in the organization. The way of rewarding employees who demonstrate ethical behaviour and disciplining unethical behaviour is consistent with the employees trust on their leader (Xu et.al, 2016). Trusted leaders act as organization's moral agents who retain and encourage the adherence to ethical standards of the organization.

\section{Trust Encourages Leaders to Learn from Failure}

Trust within an organization is an important non-physical state that enables leaders to engage in learning from their failures. When employees trust their leaders, they are likely to increase their leader's sense of confidence and that speaking up openly and honestly is expected and accepted by the employees. This allows the leaders to admit and take responsibility for their mistakes and discuss them openly. This kind of leader behaviour is indirectly associated with future quality and ethical strategic decisions through learning from failures. This process reduces a leader's tendency to oversimplify decisions, enables comprehensiveness, and promotes leaders' confidence in that they have left "no stone unturned" in the decision making process (Carmeli et.al, 2012).

\section{Trust Influences Emotions and Leader's Decision Making}

Employee trust towards the leader is regarded as an appropriate aspect for the desired execution of organizational decisions because it is considered important for getting employees to work together to obtain a common objective. The trust that employees have in their leader is a basic component for the success of leadership (Agote et.al, 2016).

Because highly trusted leaders are believed to be employee oriented and are expected to consider how their employees are affected by their decisions, they are unlikely to make decisions that threaten critical values held by their employees. As the relevance of their employee's values is a fundamental determinant of the appraisal process that causes emotional reactions, it is expected that this perceived decency of trusted leaders makes them better able to avoid producing negative emotions in their decision making (Agote et.al, 2016).

Leaders who are self-aware, whose values are based upon high ethical principles, and who act on their values, have less reason to not openly share information and express their real thoughts and 
emotions to employees. They are transparent and consistent in their beliefs, words, and actions. They are honest and show concern for their employees; they have high ethical standards, integrity and credibility (Agote et.al, 2016).

\section{Employee Trust Encourages Positive Conflict Resolutions}

Employees who trust their leaders experience admiration, loyalty, and respect towards their leaders and they are motivated to do more than they are expected to do. A trusted leader can lead the way for employees to commit to change and be involved in facilitating positive outcomes to conflicts through cooperative and collaborative problem solving. In cooperative conflict management, problems are examined from the leader's point of view on behalf of the organization and from the employee's point of view. The employee's point of view examines the extent to which an employee is interested in his own individual benefits and his own concerns, and also the extent to which the employee considers the benefits of the organization. Integrating these three viewpoints is necessary to produce the cooperative intent of managing conflict and to help employees consider their own goals in relation to those of the organization. Thus, trust in leadership leads to the development of a situational environment that will promote ethical and cooperative conflict management (Yang, 2012).

\section{Trust is a Mediator between Ethical Leadership \& Performance}

As trusted leaders exhibit self-awareness, relational transparency, an ethical perspective and a consistent and balanced method of assessing information, the outcome of their decisions can be expected to promote a trusting relationship with their employees because these behaviours demonstrate accommodation and consideration towards the employees. When trusted leaders take an ethical approach to decision making and participate in a balanced review of information instead of making quick decisions, employees may be more willing to place extra trust in their leader's future actions because they can use past experiences to predict future responses (Clap-Smith et.al, 2009).

In an organization where employees trust their leaders, each individual leader may see their employee's loyalty and increase their own loyalty and ethical standards. Higher levels of trust are eventually expected to contribute to higher levels of growth and sustainable performance in an organization. Therefore, employees' impression of ethical leadership will contribute to employee's trust within an organization's leadership and in turn result in a positive working relationship (ClapSmith et.al, 2009).

\section{Trust Encourages Risk Taking Behaviour}

Trust is an important precursor to risk-taking behaviour. Leaders intelligently encourage their employees to rethink problems and take risks. Thus, if a leader wishes to motivate their employees to take risks and explore new alternatives, they may have to set a personal example in order to prove the worthiness of their trust by the employees (Pillai et.al, 1999).

Mishra, 1996 (as cited in Pillai et.al, 1999) indicates that trust in the leader plays a very significant role in organizational crisis and transformation through its effect on unchanged and truthful communication, collaboration among critical areas within the organization and decentralized decision making. Possible effects of employee trust on the leader include commitment, satisfaction, and overall good behaviour. Commitment involves a high level of identification with the organization's goals and values, a desire to put extra effort for the benefit of the organization, and a strong willingness to maintain membership in the organization. Ethical decisions and commitment are preserved during organizational downturns if trust has been established with employees. (Pillai et.al, 1999) suggests that "all leaders require trust as a basis for their legitimacy and as the mortar that binds leader to employee". 


\section{Trust is a Mediator of Effective and Ethical Leadership}

Trust in the decision-making ability of the organization's leadership predicts overall satisfaction with the organization better than employee participation in decision-making (Casimir et.al, 2006). Employee trust in the leader is one of the most important variables that can mediate the ethicality and effectiveness of leadership in terms of producing performance outcomes. In contrast to employees who do not trust their leaders, employees who do trust their leaders are very likely to apply extra effort and acquire high levels of satisfaction because of the positive emotions connected with trust. In this way, trust can operate as a mediator of the leadership performance relationship (Carmeli et.al, 2012).

\section{When there is no Trust}

Progressive leaders build and sustain employee's trust through their leadership behaviour. A successful leader understands his or her employee's individual capabilities and personal needs, and they show that they care about their employees; these kinds of leaders are usually always trusted (Yasir et.al, 2016). Holtz \& Harold, 2008 (as cited in Yasir et.al, 2016) states that when leaders are trusted, they show individualized support towards employees and they encourage teamwork and acceptance of group goals. Such leaders normally act in a way that promotes respect, pride, and confidence of their employees, therefore, employees who believe that their leaders are involved in a constructive form of leadership behaviour will have a higher degree of trust in their leader. Judge, 2011 (as cited in Yasir et.al, 2016) found that a leader's decision-making process to bring changes in the capacity of an organization requires the trust of employees in their leadership. Therefore, attempts to bring change in an organization are normally constrained if employee's trust in their leadership is not adequate. Besides, employee's trust in their leader and organization makes them to be more committed to bring change with greater devotion; thus, the trusting employees become an aide in the overall ethicality required by the leader to bring change in an organization.

Trust is important to leaders because of the need to prompt and encourage employee commitment towards the leader's vision. Leaders who are not trusted by their employees usually lack confidence and it becomes very unlikely that such a leader can successfully achieve employee commitment to a vision, their lack of confidence reduces the appeal of the vision. This lack of trust and confidence might stimulate risk-taking behaviour in the leader and cause him to make unethical decisions (Casimir et.al. 2006).

Leaders who are not trusted by their employees may be less likely to be honest and considerate with their decisions. That is, unethical behaviour such as distorting and manipulating information or violating the organizational norms may be the result of defensive behaviour caused by a lack of employee trust (Haesevoets, 2016). Leaders who are not trusted by their employees are likely to expect unethical behaviour within the organization, and thus feel less obliged to respond to or consider their own ethical standards (Sobral \& Islam, 2013).

Leaders who do not trust their employees rarely discuss their mistrust with them, instead, they act on it. They resist the employee's attempts to influence their decisions and they suspect the employee's organizational and personal goals and reject their views (Zand, 1997). Such leaders are generally not open or honest with their employees and they deny them the opportunity to evaluate their results and decisions, but they want the employees to accept them and follow their influence.

\section{Conclusion}

This study highlights the role that employee trust plays on ethical leadership decision making. The concept of trust in leaders has been studied within a number of different fields, including psychology, 
management, ethics, and other related disciplines (Dirks and Ferrin, 2002). In an organisational setting, trust between employee and leader is significant, with trust increasing the level of cooperative relationships, which can provide important positive outcomes for organisations (Brower et al., 2008). In addition, ethical leadership is crucial in the business world for two reasons. First, unethical leadership decisions may cause employee unhappiness and distrust, resulting in low organisational effectiveness and profitability (Keselman, 2012). Second, a recent number of business scandals have made firms realise the great risk involved in facing such an event ( $\mathrm{Lu}$ and Lin, 2014). In this paper, the relationship between employee trust and ethical leadership decision making was researched. Although there has been no empirical study demonstrating exactly how employee trust affects leadership decisions in terms of ethics, previous studies related to trust and ethical decision making have been examined. Previous studies about behavioural reasoning theory, social learning theory, performance pressure on leaders, and leadership stress were used to set up links to highlight how employee trust affects leadership decision making in terms of ethics. Interestingly, employee trust may also have a negative impact on leadership ethical decision making due to increased levels of stress on behalf of the leader.

One of the findings of this study is that leaders who are trusted by their employees rely on transparent communication with their employees. It has been shown that such leaders encourage communication within the working environment and they see employee engagement in decision making as an important element of their jobs. Through trust and open communication, leaders act as internal coaches in their organizations and they encourage employees' feedback. The trust that employees show to their leaders encourages them to be open and truthful with information that is valuable to the employees and to the organization, thus becoming moral agents of their own organizations. This study also links employee trust and incentives to an increased willingness on the part of leaders to involve employees in decision making and eventually to organizational performance. Leaders are unlikely to involve employees in decision making unless they (employees) have trust in them. Involving employees is also related to increased productivity, more innovation and it amplifies employee morale.

When leaders are trusted by their employees, they easily accept their mistakes and acknowledge their failures when they have not been successful. In doing so, they become transparent with their employees and also become consistent with their words and actions. The study also found out that when there is trust on the leader, it becomes easy to resolve conflicts within an organization which in turn results in a positive working relationship.

Leaders who are not trusted by their employees lack confidence in their decisions and do not always take responsibility of their unethical decisions. They tend to be defensive to their decisions and they feel not obliged to consider their own ethical standards and they are generally not open and honest.

\section{References}

Agote, L., Aramburu, N. \& Lines, R., (2016). “Authentic Leadership Perception, Trust in the Leader, and Followers' Emotions in Organizational Change Processes. Journal of Applied Behavioural Science, Vol. 52, no. 1, 35-63.

Bergman, J, Rentsch, J, Small, E, Davenport, S, \& Bergman, S., (2012), 'The Shared Leadership Process in Decision-Making Teams', Journal of Social Psychology, Vol. 152, no. 1, 17-42.

Bianchi, E.C., Brockner, J., van den Bos, K., Seifert, M., Moon, H., van Dijke, M. \& De Cremer, D., (2015). Trust in decision-making authorities dictates the form of the interactive relationship between outcome fairness and procedural fairness. Personality and Social Psychology Bulletin, 41(1)19-34.

Brower, H. H., Lester, S. W., Korsgaard, M. A., and Dineen, B. R. (2008). A closer look at trust between managers and subordinates: Understanding the effects of both trusting and being trusted on subordinate outcomes. Journal of Management. Vol. 35, 327-347 
Brown, M. E., and Mitchell, M. S. (2010). Ethical and unethical leadership: Exploring new avenues for future research. Business Ethics Quarterly, 20(04), 583-616.

Brown, M. E., Treviño, L. K., and Harrison, D. A. (2005). Ethical leadership: A social learning perspective for construct development and testing. Organizational behavior and human decision processes, 97(2), 117-134

Brown, M. E., and Treviño, L. K. (2006). Ethical leadership: A review and future directions. The leadership quarterly, 17(6), 595-616.

Carmeli, A., Tishler, A. \& Edmondson, A.C., (2012). CEO Relational Leadership and Strategic Decision Quality in Top Management Teams: The role of team trust and learning from failure. Strategic Organization, 10 (1), 31-54.

Caldwell, C., Hayes, L.A., Bernal, P. \& Karri, R., (2008). Ethical stewardship-implications for leadership and trust. Journal of business ethics, 78(1-2), 153-164.

Clapp-Smith, R., Vogelgesang, G.R. \& Avey, J.B. (2009), Authentic leadership and positive psychological capital: The mediating role of trust at the group level of analysis, Journal of Leadership and Organizational Studies, 15(3), 227-240.

Casimir, G., Waldman, D., Bartram, T., \& Yang, S., (2006), Trust and the relationship between leadership and follower performance: Opening the black box in Australia and China, Journal of Leadership and Organizational Studies, 12, 7288 .

Chughtai, A., Byrne, M., \& Flood, B. (2015). Linking ethical leadership to employee well-being: The role of trust in supervisor. Journal of Business Ethics, 128(3), 653-663.

Colquitt, J. A., Scott, B. A., and Lepine, J. A. (2007). Trust, trustworthiness, and trust propensity: a meta-analytic test of their unique relationships with risk taking and job performance. Journal of applied psychology, 92(4), 909.

Dirks, K. T., and Ferrin, D. L. (2002). Trust in leadership: meta-analytic findings and implications for research and practice. Journal of Applied Psychology, 87(4), 611.

Engelbrecht, A. S., Heine, G., and Mahembe, B. (2014). The influence of ethical leadership on trust and work engagement: An exploratory study. SA Journal of Industrial Psychology, 40(1), 9-pages.

Ethics Resource Center. (2012). National business ethics survey of fortune 500 employees. Washington, DC: Ethics Resource Center.

Frazier, M. L., Tupper, C., and Fainshmidt, S. (2016). The path (s) to employee trust in direct supervisor in nascent and established relationships: A fuzzy set analysis. Journal of Organizational Behavior, 1(1), 20-45.

Ferrin, D.L., Bligh, M.C. \& Kohles, J.C., (2007). Can I trust you to trust me? A theory of trust, monitoring, and cooperation in interpersonal and intergroup relationships. Group \& Organization Management, 32(4), 465-499.

Gomibuchi, S. (2004). Trust and leadership. Political Science, 56(2), 27-38.

Hansen, S. D., Dunford, B. B., Alge, B. J., and Jackson, C. L. (2015). Corporate Social Responsibility, Ethical Leadership, and Trust Propensity: A Multi-Experience Model of Perceived Ethical Climate. Journal of Business Ethics, 1-14.

Hasel, M. C. (2013). A question of context: the influence of trust on leadership effectiveness during crisis. Management, 16(3), 264-293.

Haesevoets, T., Joosten, A., Reinders-Folmer, C., Lerner, L., De Cremer, D. \& Van Hiel, A., (2016). “The Impact of Decision Timing on the Effectiveness of Leaders' Apologies to Repair Followers' Trust in the Aftermath of Leader Failure". Journal of Business and Psychology, 31(4), 533-551.

Hsieh, C. \& Wang, D., (2015). "Does supervisor-perceived authentic leadership influence employee work engagement through employee-perceived authentic leadership and employee trust?" International Journal of Human Resource Management, 26(18), 2329-2348.

Jackson, B. and Parry, K. (2011). A very short fairly interesting and reasonably cheap book about studying leadership. Sage.

Jafri, M. H. (2011) Impact of Employee Trust on Organizational Commitment and Innovative Behaviour of Employees: An Empirical Study on Public Sector Employees in Bhutan.

Jiang, L. \& Probst, T.M., (2016). The moderating effect of trust in management on consequences of job insecurity. Economic and Industrial Democracy, 5-15.

Keselman, D. (2012). Ethical leadership. Holistic nursing practice, 26(5), 259-261.

Kimmel, A.J., Smith, N.C. \& Klein, J.G., (2011). "Ethical decision making and research deception in the behavioural sciences: An application of social contract theory". Ethics and Behavior, 21 (3), 222-251.

Kovač, J., and Jesenko, M. (2010). The connection between trust and leadership styles in Slovene organizations. Journal for East European Management Studies, 9-33.

Kodish, S., (2014). Communicating Organizational Trust: An Exploration of the Link between Discourse and Action. International Journal of Business Communication, 10-25. 
Lau, D. C., and Liden, R. C. (2008). Antecedents of coworker trust: leaders' blessings. Journal of Applied Psychology, 93(5), 1130.

Lee, W. S., and Selart, M. (2014). The influence of emotions on trust in ethical decision making. Problems and Perspectives in Management, 12(4), 573-580.

Lee, P., Gillespie, N., Mann, L. \& Wearing, A. (2010). "Leadership and trust: Their effect on knowledge sharing and team performance", Management Learning, 41 (4), 473-491.

Lu, C. S., and Lin, C. C. (2014). The effects of ethical leadership and ethical climate on employee ethical behavior in the international port context. Journal of Business Ethics, 124(2), 209-223.

Loi, R., Ao, O.K.Y. \& Xu, A.J., (2014). Perceived organizational support and co-worker support as antecedents of foreign workers' voice and psychological stress. International Journal of Hospitality Management, 36, 23-30.

Mishra, K., Boynton, L. \& Mishra, A., (2014). Driving Employee Engagement: The Expanded Role of Internal Communications. International Journal of Business Communication, 51(2), 183-202.

McCauley, D.P. \& Kuhnert, K.W., (1992). A theoretical review and empirical investigation of employee trust in management. Public Administration Quarterly, 1, 265-284.

Nikoi, A. A. (2009). Ethical leadership and business decision making in contemporary times. International Journal of Business and Management, 3(10), 183.

O'Fallon, M. J., and Butterfield, K. D. (2005). A review of the empirical ethical decision-making literature: 19962003. Journal of business ethics, 59(4), 375-413.

Olson, B.J., Parayitam, S. \& Bao, Y., (2007). Strategic decision making: The effects of cognitive diversity, conflict, and trust on decision outcomes. Journal of Management, 33(2),196-222.

Pillai, R., Schriesheim, C.A. \& Williams, E.S., (1999). "Fairness perceptions and trust as mediators for transformational and transactional leadership": A two-sample study. Journal of Management, 25(6), 897-933.

Tzafrir, S. S., and Dolan, S. L. (2004). Trust me: a scale for measuring manager-employee trust. Management Research: Journal of the Iberoamerican Academy of Management, 2(2), 115-132.

Selart, M., and Johansen, S. T. (2011). Ethical decision making in organizations: The role of leadership stress. Journal of Business Ethics, 99(2), 129-143.

Sørensen, O. H., Hasle, P., and Pejtersen, J. H. (2011). Trust relations in management of change. Scandinavian Journal of Management, 27(4), 405-417.

Soutar, G., McNeil, M. M., and Molster, C. (1994). The impact of the work environment on ethical decision making: Some Australian evidence. Journal of Business Ethics, 13(5), 327-339.

Stenmark, C. K., and Mumford, M. D. (2011). Situational impacts on leader ethical decision-making. The Leadership Quarterly, 22(5), 942-955.

Steinbauer, R., Renn, R. W., Taylor, R. R., and Njoroge, P. K. (2014). Ethical leadership and followers' moral judgment: The role of followers' perceived accountability and self-leadership. Journal of Business Ethics, 120(3), 381-392.

Spritzer G. M., \& Mishra A. K. (1999). “Giving up control without losing control”: Trust and its substitutes' effects on managers' involving employees in decision making. Group \& Organization Management, 24, 155-187.

Sobral, F. \& Islam, G., (2013). Ethically Questionable Negotiating: The Interactive Effects of Trust, Competitiveness, and Situation Favourability on Ethical Decision Making. Journal of Business Ethics, 117 (2), 281-296.

Van Den Akker, L., Heres, L., Lasthuizen, K., and Six, F. (2009). Ethical leadership and trust: It's all about meeting expectations. International Journal of Leadership Studies, 5(2), 102-122.

Wang, H., Tsui, A. S., and Xin, K. R. (2011). CEO leadership behaviors, organizational performance, and employees' attitudes. The Leadership Quarterly, 22(1), 92-105.

Wang, Y., (2002). Which Managers Trust Employees? Ownership Variation in China's Transitional Economy, Asia Pacific Business Review, 9(2), 138-157

Wheatcroft, J.M., Alison, L.A. \& Mcgrory, D., (2012). "The Influence of Trust on Senior Investigating Officers' Decision Making in High-Profile Critical Incidents". Police Quarterly, Vol. 15 no. 4, 386-413.

Weibel, A., Den Hartog, D. N., Gillespie, N., Searle, R., Six, F., and Skinner, D. (2016). How do controls impact employee trust in the employer?. Human Resource Management, 55(3), 437-462.

Westaby, J. D., Probst, T. M., and Lee, B. C. (2010). Leadership decision-making: A behavioral reasoning theory analysis. The Leadership Quarterly, 21(3), 481-495. 
Whitener, E. M. (1998). The impact of human resource activities on employee trust. Human Resource Management Review, 7(4), 389-404.

Wood, J. (2001). Ethical decision making. Journal of PeriAnesthesia Nursing, 16(1), 6-10.

Xu, A.J., Loi, R. \& Ngo, H., (2016). "Ethical Leadership Behaviour and Employee Justice Perceptions: The Mediating Role of Trust in Organization". Journal of Business Ethics, 134 (3), 493-504.

Yang, C. (2014). Does ethical leadership lead to happy workers? A study on the impact of ethical leadership, subjective well-being, and life happiness in the Chinese culture. Journal of business ethics, 123(3), 513-525.

Yang, Y., (2012), "Studies of transformational leadership in consumer service: Leadership trust and the mediatingmoderating role of cooperative conflict management", Psychological reports, 110 (1), 315-337.

Yasir, M., Imran, R., Irshad, M.K., Mohamad, N.A. \& Khan, M.M. (2016) “Leadership Styles in Relation to Employees' Trust and Organizational Change Capacity". SAGE Open, Vol. 6, no. 4, pp. 1-12

Zand, D.E., (1997), The Leadership Triad: Knowledge, Trust, and Power, Oxford University Press, New York. 